that encourages UK renewable energy is not going to meet all our future energy needs; my heating should be based on a $400 \%$ efficient electric air-source heat pump; turning off mobile-phone chargers is almost, but not quite, irrelevant. Insulating my house was a good idea.

In fact, MacKay brings a highly personal account of the actions he has taken to reduce his carbon footprint - and this personal aspect is hugely entertaining. Some of the data presented has been derived from measurements made during the dayto-day life of the author, and his merry commentary on the conclusions, especially when they explode popular myths, trample on various orthodoxies or run into the brick walls of present political reality, really brings the book to life and makes it a joy to read.

In the next edition there could be some structural improvements. At present it is unclear who the target audience is - in places it reads like a text book to educate policy makers and in other parts a manifesto for mass action. Indeed, it is structured as if it were two books: the first examining UK renewable energy sources in detail, which concludes that it would be challenging to meet our energy needs in this way; the second examining solutions (including renewables-only options) that would work. This separation can perhaps be eliminated, leading to a more integrated volume, which would permit a less UK-focused analysis (broadening the readership) and naturally allow the introduction of more issues, such as the impact of population growth (which is not discussed).

Nevertheless, this is a hugely important book - its content needs to enter the public consciousness. We all need to understand what it says and at least be familiar with and ideally be able to manipulate or even derive the data it contains. This book should form the backbone of the national science curriculum; there should be a blockbuster documentary movie; the BBC should commission a ten-part series hosted by Jeremy Clarkson taking us through each chapter. Only with a sea-change in public consciousness will we all become environmentalists with ideas that work, be able to silence the nimby 'conservationists' and create a generation of politicians who can actually stand on a political platform that will meet our objectives.

Although the Department of Energy may be the best place to work out the details of the economic models and the most suitable implementation plan for realizing an optimal scheme for the UK, while creating jobs and exports, MacKay could perhaps enhance his impact by leaving this to the consultants at the Department of Energy and Climate Change - where he became Chief Scientific Advisor following the publication of this book - and instead use the media to better educate us all.

\section{REVIEWED BY NEIL WILSON}

Neil Wilson is Chief Executive Officer of

Camfridge Ltd, St John's Innovation Centre, Cowley

Road, Cambridge CB4 OWS, UK.

e-mail:nwilson@camfridge.com

\title{
Music of the spheres, and the planes
}

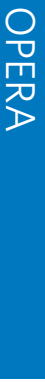

Two operas inspired by physics are currently playing in cities around Europe, with performances to come in the USA.

Premiered in September in Linz, Austria, Kepler is the latest work by composer Philip Glass, with a libretto by Martina Winkel. Just as other physicists have inspired earlier operas by Glass - Einstein on the Beach and Galileo Galilei - so the work of German mathematician and astronomer Johannes Kepler, who devised his laws of planetary motion in the early seventeenth century, becomes the basis of a musical exploration of the cosmos and the nature of science.

Kepler was a resident of Linz for several years, and this year the city is European Capital of Culture. Kepler the opera (pictured) is running now and through to January 2010 at the Landestheater Linz. Three extra concert performances are to be given on 18, 20 and 21 November at the Brooklyn Academy of Music, New York, by the Bruckner Orchestra Linz, conducted by Dennis Russell Davies.

Also tackling matters cosmological is Hypermusic Prologue: A Projective Opera in Seven Planes. Composed by Hèctor Parra,

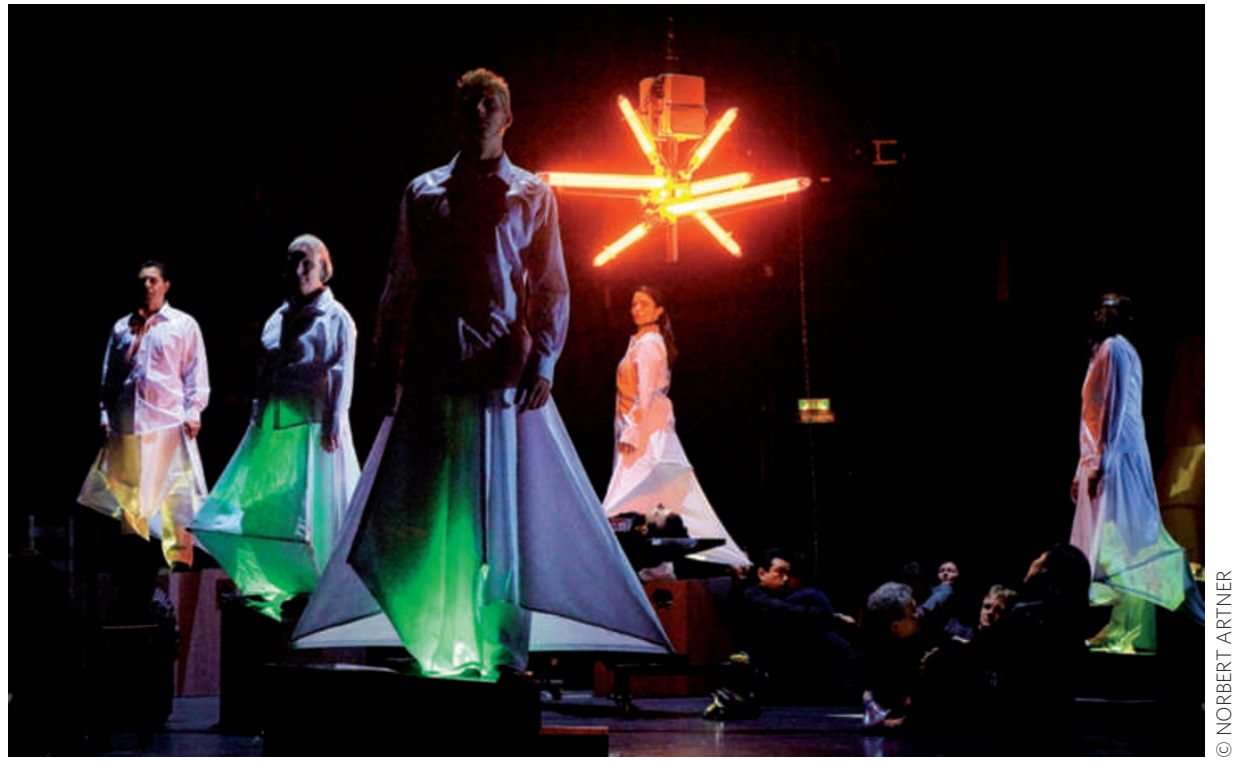

the libretto has been written by Harvard theoretician Lisa Randall - a collaboration born out of Randall's 2005 book, Warped Passages: Unravelling the Universe's Hidden Dimensions. Performed by solo soprano and baritone voices, the 'seven planes' of the title reference the extra dimensions of space postulated to exist beyond our threedimensional experience, and the seven acts of the hour-long show.
Following its premier at the Centre Pompidou, Paris, in the summer, Hypermusic Prologue will be performed on 27 and 28 November at the Gran Teatre del Liceu in Barcelona; on 6 December as part of the Rainy Days Festival in Luxembourg; and also next year at New York's Guggenheim Museum and Brussels' Kaaitheater.

\section{ALISON WRIGHT}

